\title{
Comparison of AOD between CALIPSO and MODIS: significant differences over major dust and biomass burning regions
}

\author{
X. Ma, K. Bartlett, K. Harmon, and F. Yu \\ Atmospheric Sciences Research Center, State University of New York, 251 Fuller Road, Albany, New York 12203, USA \\ Correspondence to: Xiaoyan Ma (xma@albany.edu)
}

Received: 24 October 2012 - Published in Atmos. Meas. Tech. Discuss.: 16 November 2012

Revised: 5 July 2013 - Accepted: 5 August 2013 - Published: 16 September 2013

\begin{abstract}
Cloud-Aerosol Lidar and Infrared Pathfinder Satellite Observations (CALIPSO) provide global vertical profiles of aerosol optical properties for the first time. In this study, we employed about 6 yr (2006-2011) of CALIPSO level 3 monthly mean gridded aerosol optical depth (AOD) products (daytime and nighttime) for cloud-free conditions, to compare with the Moderate Resolution Imaging Spectroradiometer (MODIS) Terra/Aqua level 3 monthly mean AOD dataset for the same time period. While the spatial distribution and seasonal variability of CALIPSO AOD is generally consistent with that of MODIS, CALIPSO is overall lower than MODIS as MODIS has higher frequency than CALIPSO for most bins of AOD. The correlation between MODIS and CALIPSO is better over ocean than over land. We focused on four regions that have large systematic differences: two over dust regions (the Sahara and Northwest China) and two over biomass burning regions (South Africa and South America). It is found that CALIPSO AOD is significantly lower than MODIS AOD over dust regions during the whole time period, with a maximum difference of 0.3 over the Saharan region and 0.25 over Northwest China. For biomass burning regions, CALIPSO AOD is significantly higher than MODIS AOD over South Africa, with a maximum difference of 0.25 . Additionally CALIPSO AOD is slightly higher than MODIS AOD over South America for most of the time period, with a few exceptions in 2006, 2007, and 2010, when biomass burning is significantly stronger than during other years. We analyzed the impact of the satellite spatial and temporal sampling issue by using level 2 CALIPSO and MODIS products, and these systematic differences can still be found. The results of this study indicate that systematic differences of CALIPSO relative to MODIS are closely associated with aerosol types, which vary by location
\end{abstract}

and season. Large differences over dust and biomass burning regions may suggest that assumptions made in satellite retrievals, such as the assumed lidar ratios for CALIPSO retrievals over dust and biomass burning regions or the surface reflectance information and/or the aerosol model utilized by the MODIS algorithm, are not appropriate.

\section{Introduction}

Aerosols play an important role in global climate change by scattering and/or absorbing radiation and altering cloud properties. However, estimation of the radiative forcing by aerosols is very uncertain due to a lack of knowledge of the microphysical and optical properties of aerosol particles and their nonhomogeneous spatial distribution. In the last few decades, aerosol properties have been studied by conducting intensive field campaigns. However, field observations are generally limited in temporal and spatial coverage. In contrast, satellite observations provide long-term, uninterrupted spatial coverage, an effective tool for monitoring the global aerosol distribution and properties. Aerosol optical depth (AOD) has been provided by various satellite sensors such as AVHRR, TOMS, MODIS, MISR, OMI, and SeaWiFs. Due to these products being passive sensor measurements, they mainly provide total column values with little information on the vertical distributions of aerosols, which are crucial for the radiative effect of aerosols (Zarzycki and Bond, 2010).

The launch of the Cloud-Aerosol Lidar and Infrared Pathfinder Satellite Observations (CALIPSO) provides a global profile that complements passive sensors when observing aerosols and clouds from space. Currently there 
are only limited validations of CALIPSO aerosol profiles against ground-based lidar measurements (Kim et al., 2008; Mamouri et al., 2009; Wu et al., 2011), thus it is difficult to validate the vertical profiles with the global coverage. However, it is feasible to compare the vertically integrated extinction, i.e., aerosol optical depth (AOD), with observations from other satellite sensors, such as MODIS, MISR as well as the ground-based AERONET. Such comparisons will provide valuable insights into the performance of CALIPSO profile retrievals. Yu et al. (2010) employed CALIPSO observations from June 2006 to November 2007 to compare with GOCART model simulations and MODIS retrievals. Their comparison indicated that CALIPSO AOD is generally lower than MODIS AOD in most regions. Kittaka et al. (2011) compared AOD at $532 \mathrm{~nm}$ derived from CALIPSO version 2 data, with MODIS Aqua AOD at $550 \mathrm{~nm}$ from June 2006 through August 2008. They found that AOD from CALIPSO has a small global mean relative to MODIS collection 5. Redemann et al. (2012) assessed the consistency between instantaneously collocated level 2 AOD from MODIS Aqua and CALIPSO versions 2 and 3, and found that CALIPSO V3 (in comparison to V2) is generally in better agreement with MODIS AOD. Schuster et al. (2012) compared level 2 version 3 CALIPSO AOD with measurements at 147 AERONET sites and found a CALIPSO bias of $-13 \%$ relative to AERONET for the $3 \mathrm{yr}$ period from June 2006 to May 2009.

The studies above are all based on CALIPSO level 2 products. The CALIPSO team recently released the level 3 monthly mean gridded dataset, which provides the total AOD and vertical profile of aerosol extinction in a global grid box to facilitate comparison with model validation. In this study, we compare nearly $6 \mathrm{yr}$ of CALIPSO AOD data (June 2006 through 2011) with AOD from MODIS. In contrast to the previous studies, we not only compare globalscale CALIPSO and MODIS AOD, but we also analyze the large systematic AOD differences over two dust and two biomass burning regions. Combined with the GEOS-ChemAPM model-simulated optical depth for each aerosol component, we investigate the differences between CALIPSO and MODIS by examining seasonal variability and inter-annual variation. In addition, to explore the impact of different spatial and temporal sampling in CALIPSO and MODIS on our results, we also employ level 2 products and conduct spatially and temporally collocated comparisons between the two instruments.

This paper is organized as follows. In Sect. 2, descriptions of AOD data from level 3 CALIPSO and MODIS are outlined. In Sect. 3, the results of comparisons between CALIPSO and MODIS AOD are described, with a focus on the comparisons over major dust and biomass burning regions. The spatially and temporally collocated comparisons by using level 2 products are presented in this section as well. A summary and discussion is given in Sect. 4.

\section{Satellite AOD measurements}

\subsection{CALIPSO}

CALIPSO/CALIOP was launched on April 28, 2006, with an Equator crossing time of about 13:30 and 01:30 LT and a 16-day repeating cycle (Winker et al., 2010). The main objective of the CALIPSO mission is to provide a global, multi-year dataset of cloud and aerosol spatial and optical properties from which to assess uncertainties of aerosol direct and indirect effects on climate forcing and cloud-climate feedback. The Cloud-Aerosol Lidar with Orthogonal Polarization (CALIOP) instrument, on CALIPSO, is a twowavelength (532 and $1064 \mathrm{~nm}$ ) polarization lidar. CALIOP provides substantial and unique information on vertical and geographical distributions of clouds and aerosols. CALIOP conducts nearly continuous observations of height-resolved attenuated backscatter over the globe (Sassen, 2000; Winker et al., 2003). In this study, we use level 3 monthly mean gridded $\left(2^{\circ} \times 5^{\circ}\right)$ products, which provide the aerosol extinction coefficient at $532 \mathrm{~nm}$, column aerosol optical depth, and aerosol layer properties in the global grid cell derived from the CALIPSO lidar level 2 aerosol profile product. AOD statistics are reported for four sky conditions: all sky, cloudfree, above cloud and combined. For this study we use the dataset for cloud-free condition and both the daytime and nighttime.

\subsection{MODIS}

The Moderate Resolution Imaging Spectroradiometer (MODIS) measures Top Of Atmosphere (TOA) radiances at 36 wavelengths from 0.41 to $14 \mu \mathrm{m}$. A $2330 \mathrm{~km}$ viewing swath provides near-global coverage every day. There are two MODIS sensors (King et al., 2003) observing Earth from polar orbit aboard NASA's Terra (since February 2000) and Aqua (since June 2002) satellites. The different equatorial crossing times of the two satellites, with Terra crossing at 10:30 local time and Aqua at 13:30 local time, may introduce differences in the retrieved aerosol products due to different viewing geometries returning different distributions of scattering angles and different aerosol mass and sensor calibrations. Therefore, we use the retrieved AOD products from both Terra and Aqua in this study. The MODIS AOD data (Kaufman et al., 1997; Remer et al., 2005; Levy et al., 2007) are taken from the monthly mean level 3 products from Terra (MOD08_M3.051) and Aqua (MYD08_M3.051) with a $1^{\circ} \times 1^{\circ}$ resolution and combined with the Deep Blue product, specifically retrieved for the AOD over desert regions. 


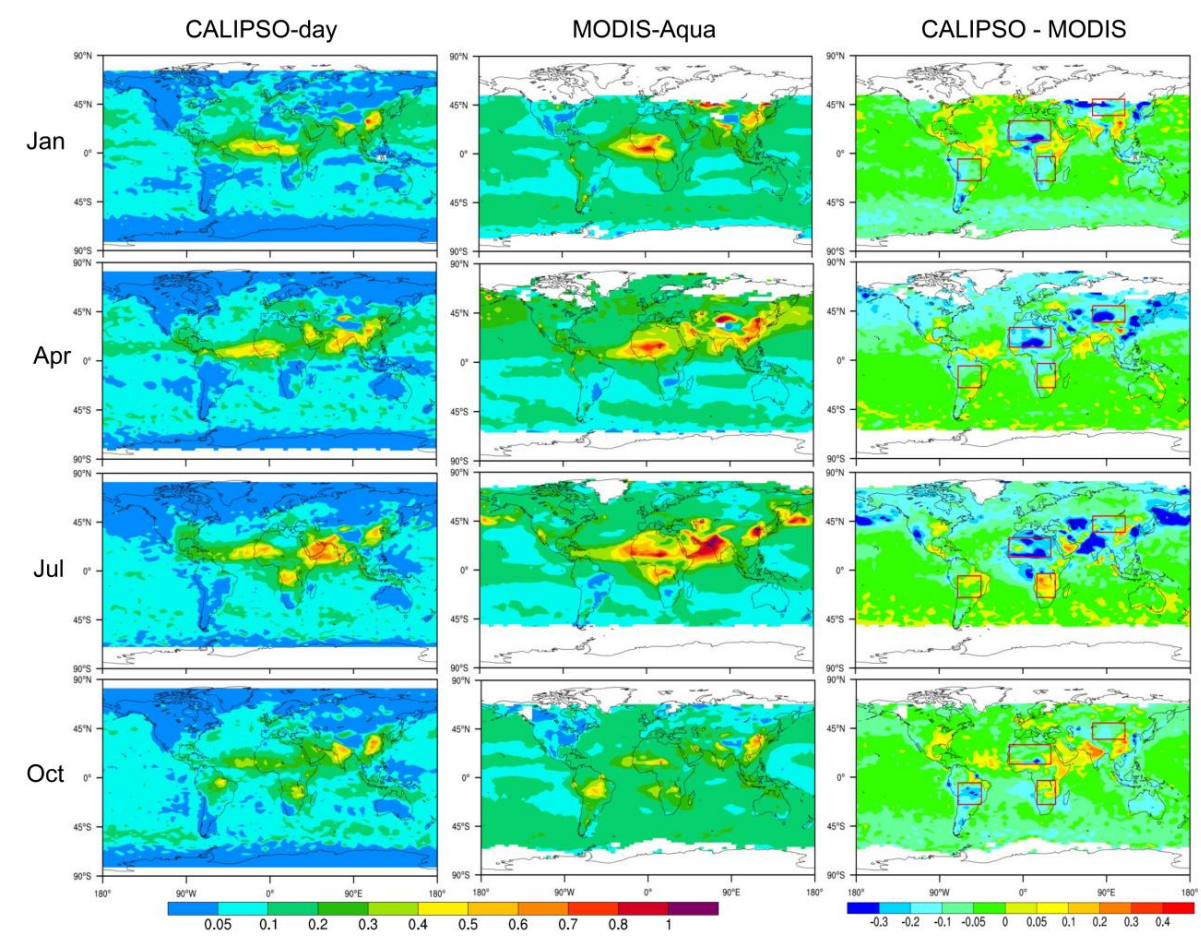

Fig. 1. Multi-year averaged (2006-2011) aerosol optical depth (AOD) from CALIPSO daytime, MODIS Aqua, and their differences in January, April, July, and October. The red rectangles shown in the right-column plots mark the regions of the Sahara, Northwest China, South Africa, and South America.

\section{Comparisons of AOD between CALIPSO and MODIS}

For comparison, MODIS monthly mean AOD data $\left(1^{\circ} \times 1^{\circ}\right)$ have been re-gridded into the same grid cell as CALIPSO $\left(2^{\circ} \times 5^{\circ}\right)$ by averaging 10 MODIS $1^{\circ} \times 1^{\circ}$ grid cells which fall within each CALIPSO grid cell $\left(2^{\circ} \times 5^{\circ}\right)$. The results are presented below.

\subsection{CALIPSO and MODIS AOD}

Figure 1 shows 6 yr (2006 to 2011) averaged CALIPSO daytime AOD at $532 \mathrm{~nm}$ (left column), MODIS Aqua AOD at $550 \mathrm{~nm}$ (middle column) and their differences (right column) in January, April, July, and October. Overall, both CALIPSO and MODIS show similar spatial distributions, e.g., the maximum AOD occurs over North and West Africa due to Saharan dust events, the maximums over East Asia, India, Europe and North America are mainly due to industrial-based fossil fuel emissions, and the South African and South American peaks are due to biomass burning. The seasonal variability shown by CALIPSO is also consistent with MODIS. For instance, both satellite datasets show high magnitudes over central West Africa in January due to biomass burning, which then shift northward in April and July due to increasing dust events, and relatively low values are shown over North Africa in October. The seasonality of biomass burning in South Africa and South America is also evident from both CALIPSO and MODIS. However, CALIPSO is systematically lower than MODIS over ocean, especially over the Southern Ocean, which is clearly shown in the right column of Fig. 1.

Figure 2 presents the results from CALIPSO nighttime AOD at $532 \mathrm{~nm}$ and MODIS Aqua AOD at $550 \mathrm{~nm}$. Although there are some differences between CALIPSO daytime and nighttime, the spatial patterns of the differences of AOD between CALIPSO nighttime and MODIS Aqua are similar to the ones shown in Fig. 1. We also compare the CALIPSO nighttime AOD to MODIS Terra, and CALIPSO daytime to MODIS Terra, and find similar features (figure omitted).

The global averaged values based on the monthly mean AOD data from June 2006 to December 2011 (Table 1) show that the CALIPSO AOD during the study period at daytime ( 0.103 over land, 0.087 over ocean) is much lower than MODIS Aqua AOD (0.193 over land, 0.140 over ocean). The CALIPSO AOD at nighttime $(0.150$ over land, 0.089 over ocean) is $46 \%$ higher than daytime over land and very close to the value over ocean, which is about $20 \%$ and $40 \%$ lower than MODIS Terra over land and ocean, respectively. The overall low CALIPSO AOD is possibly because the CALIPSO algorithms only retrieve extinction and optical depth within detected layers (Winker et al., 2009). Thus, tenuous aerosol, which is not detected, will not be retrieved. This always decreases the retrieved AOD. Winker 

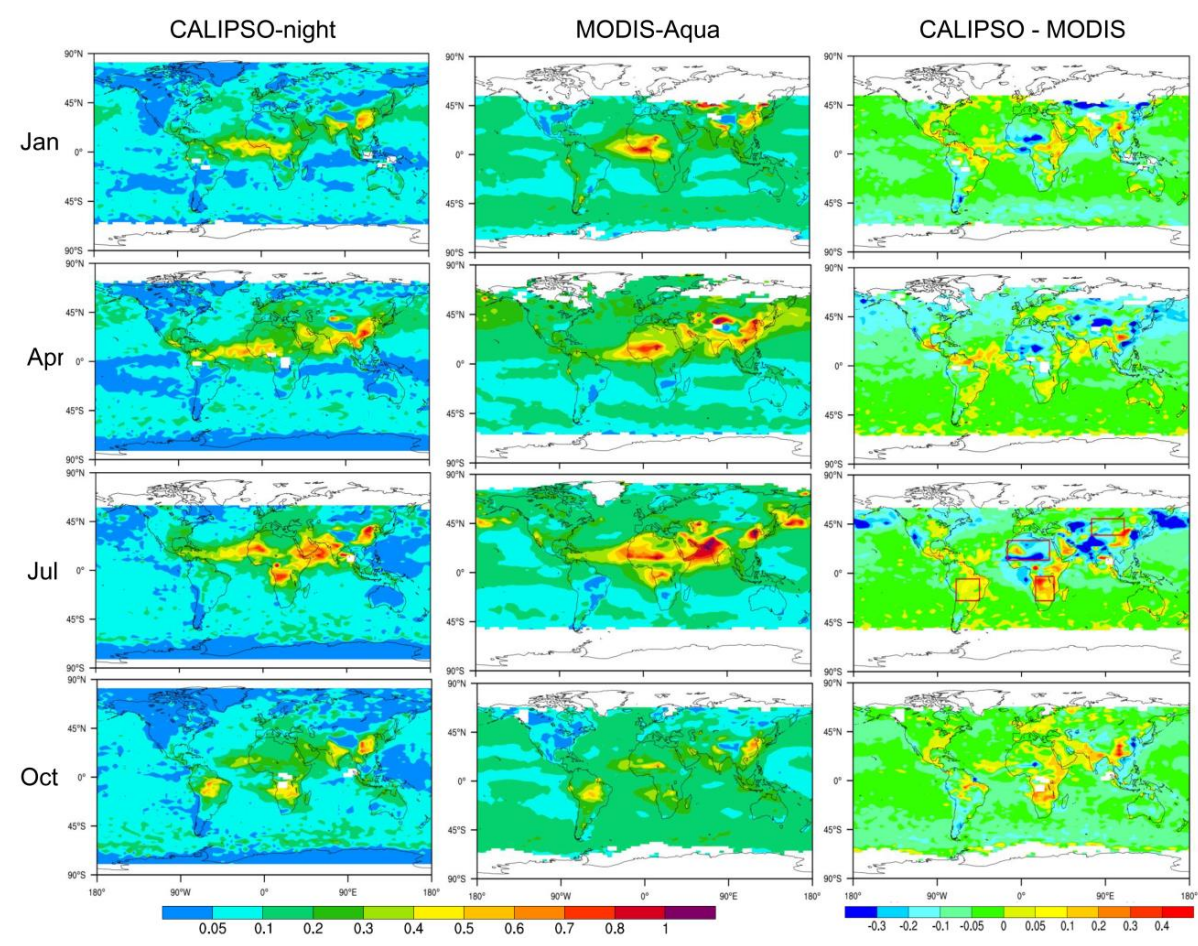

Fig. 2. Same as Fig. 1 but for the data from CALIPSO nighttime and MODIS Aqua.

Table 1. Global averaged AOD from level 3 CALIPSO daytime/nighttime and MODIS Terra/Aqua over land and ocean for the data from June 2006 until December 2011.

\begin{tabular}{lrr}
\hline & land & ocean \\
\hline CALIPSO & & \\
day & 0.103 & 0.087 \\
night & 0.150 & 0.089 \\
\hline MODIS & & \\
Terra & 0.187 & 0.148 \\
Aqua & 0.193 & 0.140 \\
\hline
\end{tabular}

et al. (2013) recently reported global mean CALIPSO AOD for daytime/nighttime by integrating averaged extinction profiles. Compared to our results, AODs reported by Winker et al. (2013) are similar over ocean, but much higher over land. In addition, day/night difference over land is slightly smaller (0.03) than in our study (0.05). It is noted that CALIPSO nighttime AOD over land (0.21) in Winker et al. (2013) is higher than MODIS Aqua, while some previous studies found that CALIPSO AODs are generally small relative to MODIS (Kittaka et al., 2011; Redemann et al., 2012). These differences may suggest there are inconsistencies which have not yet been resolved in the CALIPSO AOD data.

Figure 3 shows the two-dimensional frequency distributions of AOD values from CALIPSO daytime and MODIS (Terra/Aqua) over land and ocean for the study period.
Overall, over ocean the scatter is smaller than over land and thus better correlation between MODIS and CALIPSO is found. CALIPSO AOD is generally low relative to MODIS for both land and ocean, particularly for the smaller AOD values. It is also noticed that there is a high population in the MODIS AOD bins between 0 and 0.9 for zero CALIPSO AOD for both land and ocean.

Figure 4 shows the two-dimensional frequency distributions of AOD values from CALIPSO nightime and MODIS. Similar features are generally seen as shown in Fig. 3. Over land, a slightly better correlation is found between MODIS and CALIPSO nighttime than daytime shown in Fig. 3.

\subsection{Significant difference over major dust and biomass burning regions}

Although CALIPSO AOD is generally lower than MODIS $\mathrm{AOD}$, it is interesting to see that it is higher in some regions (i.e., positive values in the right columns of Figs. 1 and 2), specifically over regions with stronger biomass burning (e.g., South Africa). It is also shown that CALIPSO AOD is substantially lower than MODIS AOD over major dust regions (i.e., negative values in the right columns of Figs. 1 and 2), especially over the Sahara dust regions and Northwest China. Next, we analyze in detail the large systematic difference over these regions (marked in the red rectangles in Figs. 1 and 2). The GEOS-Chem-APM model simulations are also employed to assist the analysis. 

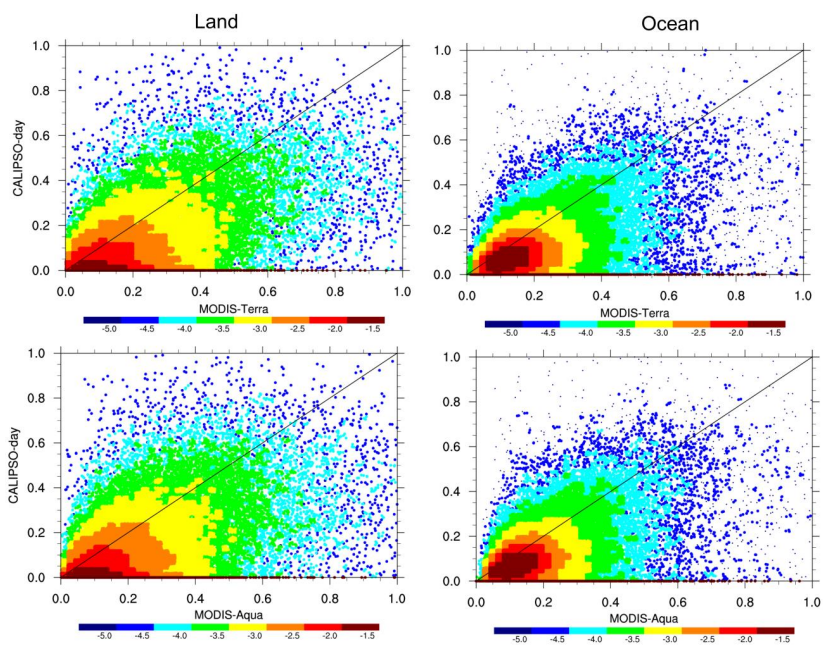

Fig. 3. Frequency distributions of AOD between MODIS (Terra/Aqua) and CALIPSO daytime for the time period from June 2006 to 2011 over land (left column) and ocean (right column). The color scale represents the fraction of the total data (in logarithm).

\subsubsection{GEOS-Chem-APM model}

The GEOS-Chem model is a global 3-D model of atmospheric composition driven by assimilated meteorological observations from the Goddard Earth Observing System (GEOS) of the NASA Global Modeling Assimilation Office (GMAO) (e.g., Bey et al., 2001). The model has been developed and used by many research groups and contains a number of state-of-the-art modules treating various chemicals and aerosols with up-to-date key emission inventories (e.g., Guenther et al., 2006; Bond et al., 2007).

The APM model, incorporated into GEOS-Chem by $\mathrm{Yu}$ and Luo (2009), is an advanced multi-type, multicomponent, size-resolved microphysics model. The basic microphysical processes in the model include nucleation, condensation/evaporation, coagulation, thermodynamic equilibrium with local humidity, and dry and wet deposition. Prognostic aerosol compositions include secondary particles (SP, containing sulfate, ammonia, nitrate and Secondary Organic Aerosols (SOAs)), black carbon (BC), primary organic carbon (OC), sea salt (SS), and mineral dust (DS). The current GEOS-Chem-APM employs 40 bins for SP to cover the dry diameter size range of $0.0012 \mu \mathrm{m}$ to $12 \mu \mathrm{m}, 20$ bins for SS to cover the dry diameter size range of $0.012 \mu \mathrm{m}$ to $12 \mu \mathrm{m}$, and 15 bins for DS particles to cover the size range of $0.03 \mu \mathrm{m}$ to $50 \mu \mathrm{m}$. In addition, two log-normal modes with one for fossil fuel (median diameter of $60 \mathrm{~nm}$ ) and another for biomass burning (median diameter of $150 \mathrm{~nm}$ ) are employed to represent hydrophobic BC, while another two lognormal modes are used for hydrophilic BC. Similarly, four log-normal modes are used to represent hydrophobic and hydrophilic OC. The formation of new particles is calculated
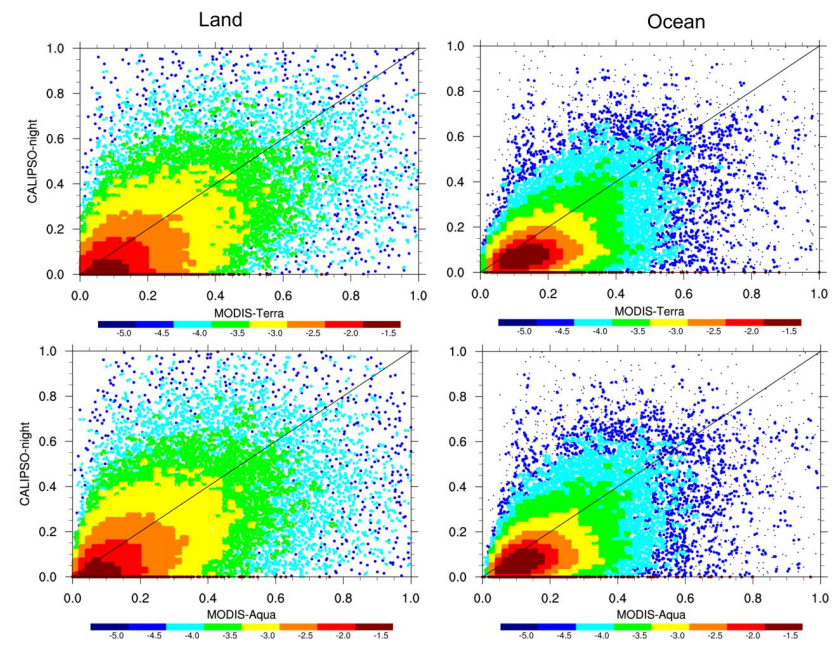

Fig. 4. Same as Fig. 3 but for CALIPSO nighttime data.

with the ion-mediated nucleation mechanism (Yu, 2010). The contributions of nitrate, ammonium, and SOAs to secondary particle growth are considered. The coating of secondary species on primary particles (sea salt, BC, OC, and dust) is explicitly simulated. The model has been validated with a large number of relevant aerosol measurements (Yu and Luo, 2009; Yu et al., 2010, 2012; Ma et al., 2012).

\subsubsection{Significant difference over major dust and biomass burning regions}

Figure 5 shows the time series of monthly mean AOD from CALIPSO daytime/nighttime and MODIS Terra/Aqua during the period from 2006 to 2011 over the Sahara, Northwest China (NWChina), South Africa, and South America. Over the Sahara, it is clearly shown that MODIS AODs (both Terra and Aqua) are always higher than CALIPSO AODs (daytime and nighttime). In addition, MODIS Aqua is generally higher than MODIS Terra while CALIPSO nighttime is usually higher than CALIPSO daytime, with the largest difference during the summer. Over NWChina, although AOD is much lower compared to the Sahara, similar behavior can be found, except the largest difference occurs in spring. Over South Africa, CALIPSO AOD is systematically higher than MODIS AOD for each year, especially during the months from July to September. Over South America, the differences between CALIPSO and MODIS are not as significant and systematic as shown in other regions. The AOD over this region shows significant inter-annual variability compared to the other regions, i.e., there are much larger magnitudes in the years 2006, 2007 and 2010 than the other years, which has also been pointed out in a previous study (Torres et al., 2010). It is interesting to note that the largest difference over South America occurs during the months July through September in the years 2006, 2007 and 2010 when AOD is substantially high. 


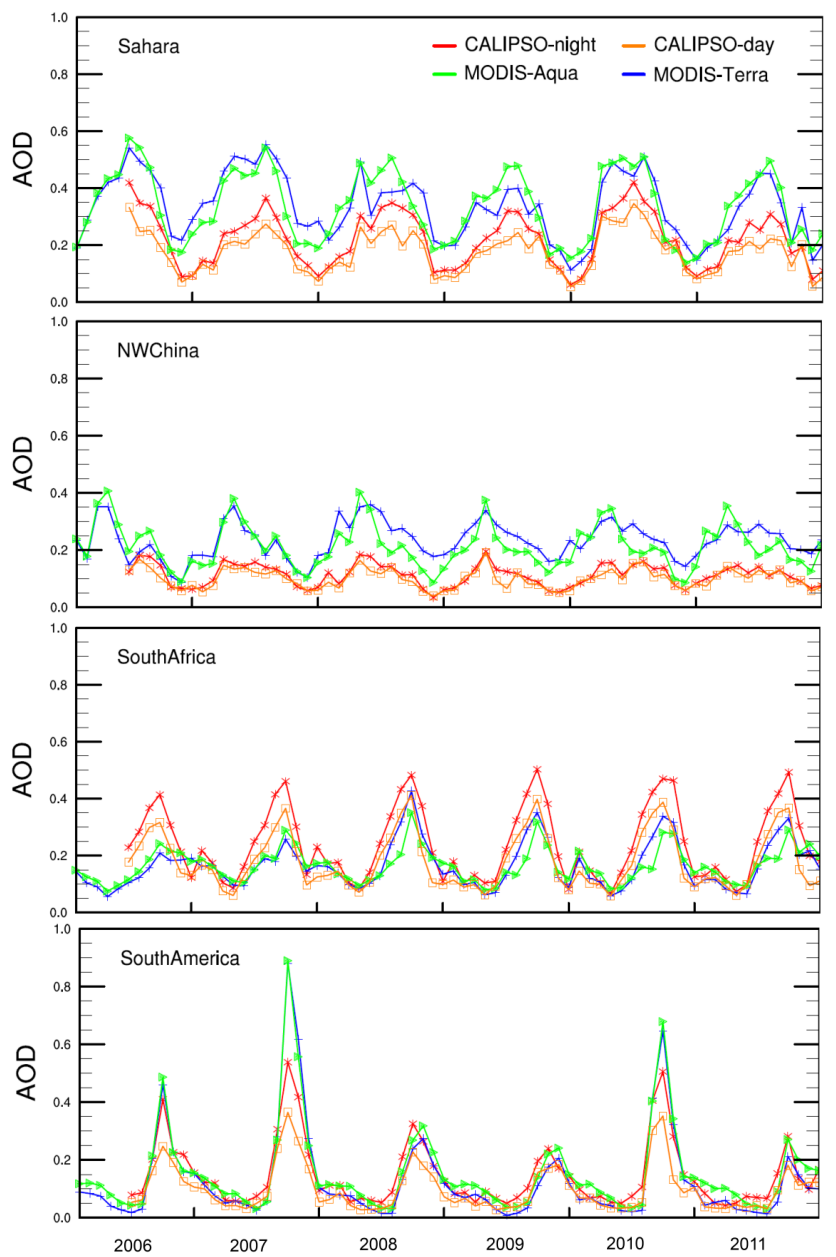

Fig. 5. Time series of AOD from CALIPSO daytime/nighttime and MODIS Terra/Aqua during the years from 2006 to 2011 over the Sahara, Northwest China, South Africa, and South America.

As discussed above, it appears that the largest difference between CALIPSO and MODIS occurs during the active dust seasons over the major dust regions, i.e., summer over the Sahara and spring over NWChina. The pattern also applies to the active biomass burning seasons over major biomass burning regions, i.e., July through September. Below, we combine the GEOS-Chem-APM-simulated AOD for each aerosol component to examine the results shown above. It should be pointed out that GEOS-Chem-APM-derived AODs of primary particles include the contribution of the secondary species coated on them, which are explicitly tracked in the model (Yu et al., 2012).

The GEOS-Chem-APM has been widely validated with various observations. Bey et al. (2001) evaluated the modelsimulated chemistry with observations. Ma et al. (2012) and $\mathrm{Yu}$ et al. (2012) compared the simulated aerosol concentrations with surface observations as well as optical properties with ground-based observations (AERONET, Holben et al., 1998) and satellite retrievals (MODIS and MISR).

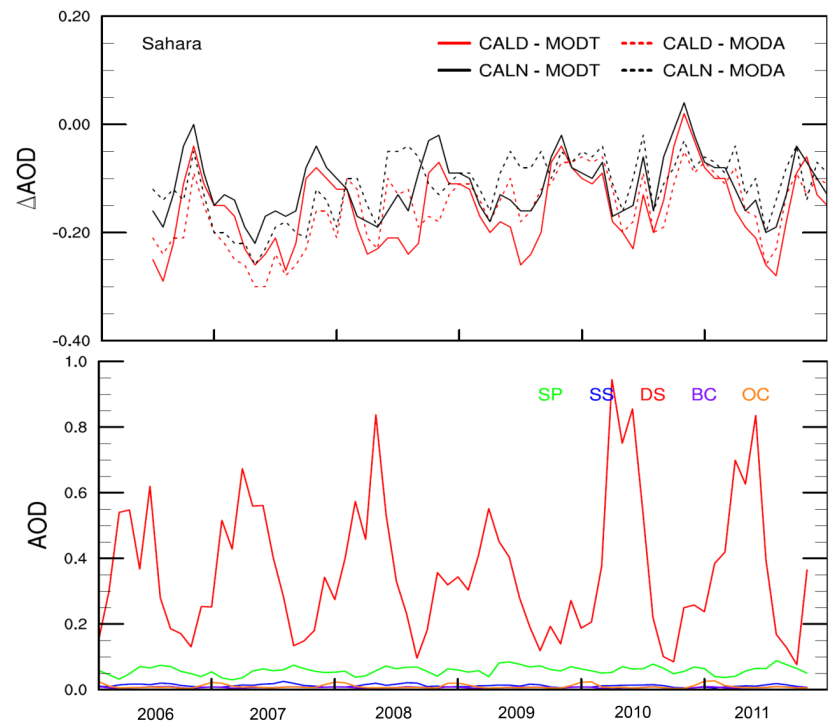

Fig. 6. Top plot shows the differences of AOD ( $\triangle \mathrm{AOD})$ between CALIPSO daytime (CALD), nighttime (CALN), and MODIS Terra (MODT) and Aqua (MODA). Bottom plot shows the GEOS-ChemAPM-simulated AOD for SP (secondary particles), SS (sea salt), DS (mineral dust), BC (black carbon), and OC (organic carbon). The results shown here are for the Sahara.

Additionally Yu and Luo (2009) evaluated the simulated particle number concentrations. Overall, the model can reasonably reproduce the spatial distribution and seasonal variations of aerosol mass and number concentrations as well as aerosol optical depth. Figures 6-9 show the time series of GEOS-Chem-APM-simulated aerosol AOD for SP, SS, DS, $\mathrm{BC}$, and $\mathrm{OC}$, together with the time series of differences of AOD ( $\triangle \mathrm{AOD}$ ) between CALIPSO daytime/nighttime (represented by CALD/CALN) and MODIS Terra/Aqua (represented by MODT/MODA). It is shown in Fig. 6 that total AOD is dominated by DS over the Sahara, as expected, while other aerosol components, such as SP, SS, OC, and BC, contribute only a small amount to the total AOD. The large difference between CALIPSO and MODIS is consistent with the peak of DS AOD, with the largest difference around -0.3 during the summer seasons. Compared to the Saharan region, DS contributes a relatively small fraction of AOD over NWChina (Fig. 7), but a large fraction is from SP and some contributions from $\mathrm{OC}$ and $\mathrm{BC}$. Therefore, while the largest $\triangle \mathrm{AOD}$ is roughly consistent with the peak of DS AOD, the magnitude is generally less than -0.25 . The results over the Sahara and NWChina indicate that satellite retrievals appear to have a large difference over the dust regions. This has been supported by the study of Schuster et al. (2012), in which they compared CALIPSO AOD with AERONET ground observations and found that the relative and absolute bias are reduced if the data containing dust are omitted. One possible reason for the difference is the uncertainty of the assumed lidar ratio over dust regions for CALIPSO retrievals. 


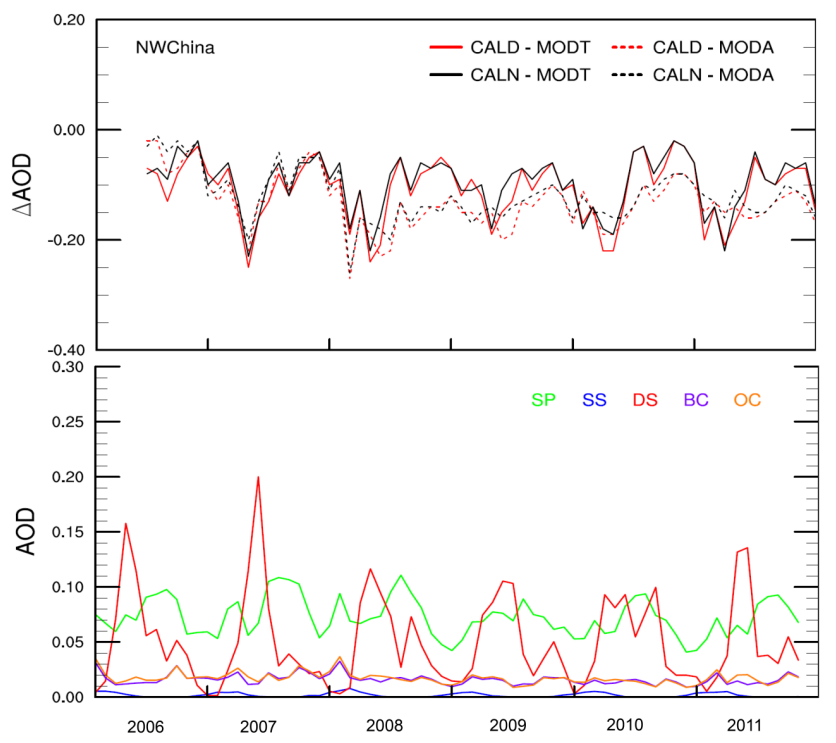

Fig. 7. Same as Fig. 6 but for Northwest China.

The results over South Africa (Fig. 8) show that secondary particles (SP) contribute the most to total AOD over this region, and that $\mathrm{OC}$ and $\mathrm{BC}$ are the second greatest contributors to this total. The consistent inter-annual cycle between SP AOD and OC/BC AOD implies that they all come from similar sources (biomass burning). Therefore the largest $\triangle \mathrm{AOD}$ between CALIPSO and MODIS corresponds to the peak of OC/BC AOD, which occurs during the biomass burning season from July to September. In contrast to South Africa, over South America (Fig. 9) SP contributes a much greater fraction of total AOD, while OC/BC contributes much less. The magnitude of $\triangle \mathrm{AOD}$ is systematically low compared with the magnitudes over South Africa, with a slightly positive $\triangle \mathrm{AOD}$ during most of the time period. A few exceptions occur in the biomass burning seasons during the years 2006, 2007 , and 2010, where the corresponding $\triangle \mathrm{AOD}$ is over -0.20 . It is noticed that they are consistent with the highest OC/BC AOD fractions of the total AOD for the years 2006, 2007, and 2010. The difference in the correlation between the $\triangle \mathrm{AOD}$ and aerosol type between South Africa and South America could be due to the different burning types. In South America, the burning is more of the smoldering type, while it is more of the flaming type in South Africa. This can cause different aerosol types from the biomass burning. The results indicate that there exist significant differences between CALIPSO and MODIS retrievals for the strong biomass burning seasons and years, suggesting that the satellite retrieval algorithms need to be improved in the case of strong biomass burning events.

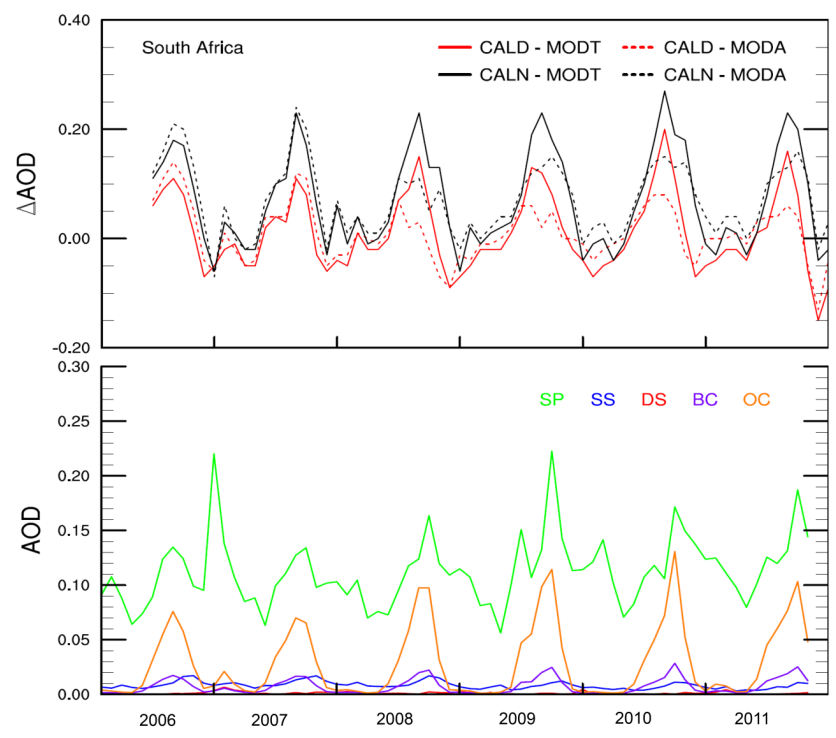

Fig. 8. Same as Fig. 6 but for South Africa.

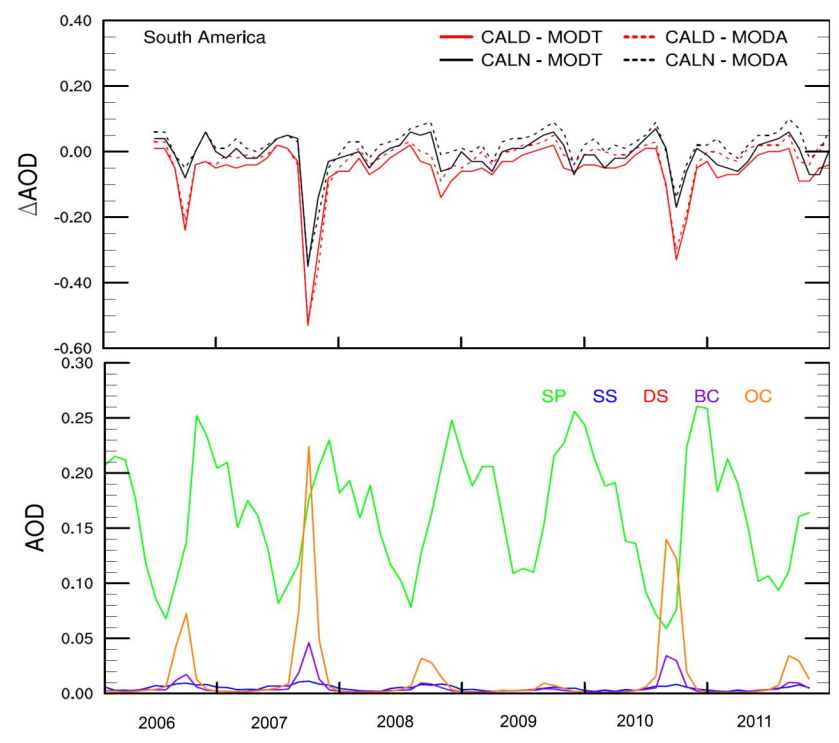

Fig. 9. Same as Fig. 6 but for South America.

\subsection{Effect of different spatio-temporal sampling on the results}

The comparisons and conclusions shown above are based on monthly $2^{\circ} \times 5^{\circ}$ CALIPSO and $1^{\circ} \times 1^{\circ}$ MODIS datasets. Since the CALIPSO/CALIOP swath is much narrower than the MODIS, it is possible that the MODIS and CALIPSO monthly means may not represent the averages from the consistent temporal and spatial coverage, which may impact the findings discussed. To explore the possible impact of differences in spatial and temporal sampling between CALIPSO and MODIS on our findings mentioned above, we employed one-year (2007) level 2 AOD retrievals from 

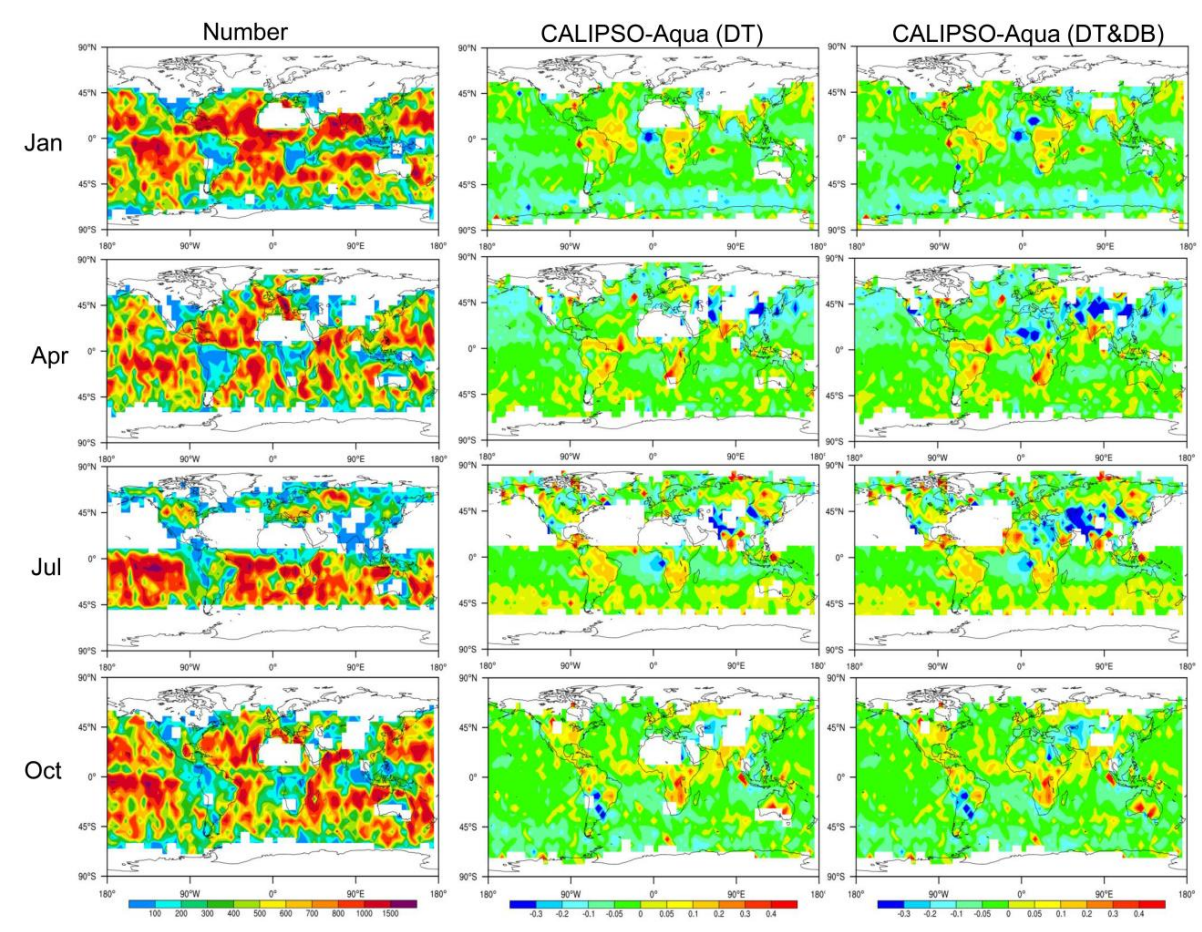

Fig. 10. The number of the CALIPSO and MODIS coincidences with valid AOD data from both instruments (left column), AOD differences between CALIPSO and MODIS Aqua from Dark Target product (middle column), and AOD differences from both Dark Target and Deep Blue products (right column), for January, April, July, and October 2007.

MODIS Aqua (C5) and CALIPSO/CALIOP version 3. The primary products compared in this paper are the $0.55 \mu \mathrm{m}$ Optical_Depth_Land_And_Ocean from the MODIS Aqua level $210 \mathrm{~km}$ aerosol data product (MYD04_L2) and the $0.532 \mu \mathrm{m}$ aerosol layer optical depth from the CALIOP level $25 \mathrm{~km}$ aerosol layer product.

Because of the large differences in spatial sampling, the comparisons in this section are based on simultaneous, colocated daytime CALIOP and MODIS observations. The orbits of the CALIPSO and Aqua satellites are controlled to keep the along-track separation at about 2 min and the relative cross-track error of the two satellite groundtracks is held at about $10 \mathrm{~km}$. Following the strategy used by Kittaka et al. (2011), spatially coincident CALIOP and MODIS AOD observations are identified when the distance between the center of a CALIOP $5 \mathrm{~km}$ "pixel" and that of a MODIS pixel is less than $10 \mathrm{~km}$. This criterion automatically selects timecoincident measurements (within $2 \mathrm{~min}$ ). Figure 10 shows the global distribution of the number of instantaneously collocated comparisons between MODIS and CALIOP in a $5^{\circ} \times 5^{\circ}$ box for January, April, July, and October in the left column and the AOD difference (CALIOP minus MODIS) in the middle column. It is seen that there are large numbers of instantaneously collocated observations made between $45^{\circ}$ to the north and south of the Equator, while the number of co-located AOD samples is limited in July in the northern mid-latitudes and subtropics because the
CALIOP footprint falls on the eastern edge of the MODIS sunglint regions, where MODIS AOD is not available. It is interesting to see that there exist relatively large differences over the biomass burning regions, which is similar to our findings shown above by using level 3 products. Over high-reflectance surface including dust regions, there is no comparison available as MODIS pixels are filled with missing values. To look at the AOD over dust regions, we also employed the retrieval product for bright surfaces (Deep_Blue_Aerosol_Optical_Depth_550_Land) from the MODIS Aqua level $210 \mathrm{~km}$ aerosol data product (MYD04_L2). The combined MODIS AOD product is based on the Dark Target (DT) AOD product, but filled with the Deep Blue (DB) AOD for the pixels with missing values. Therefore, MODIS AOD in biomass burning regions comes mainly from the Dark Target algorithm, whereas AOD in desert regions comes largely from the Deep Blue algorithm. The differences of AOD between CALIOP and MODIS combined products (DT\&DB) are shown in the right column of Fig. 10. It is noticeable that the negative difference over the Saharan region, although not so significant as shown in Fig. 2, still exists, particularly in April and July. We will not discuss the results over Northwestern China due to the large number of pixels filled with missing values there.

Figure 11 presents the time series of AOD from level 2 MODIS Aqua and CALIOP daytime in 2007, together with the level 3 monthly mean MODIS (both Aqua and Terra) and 

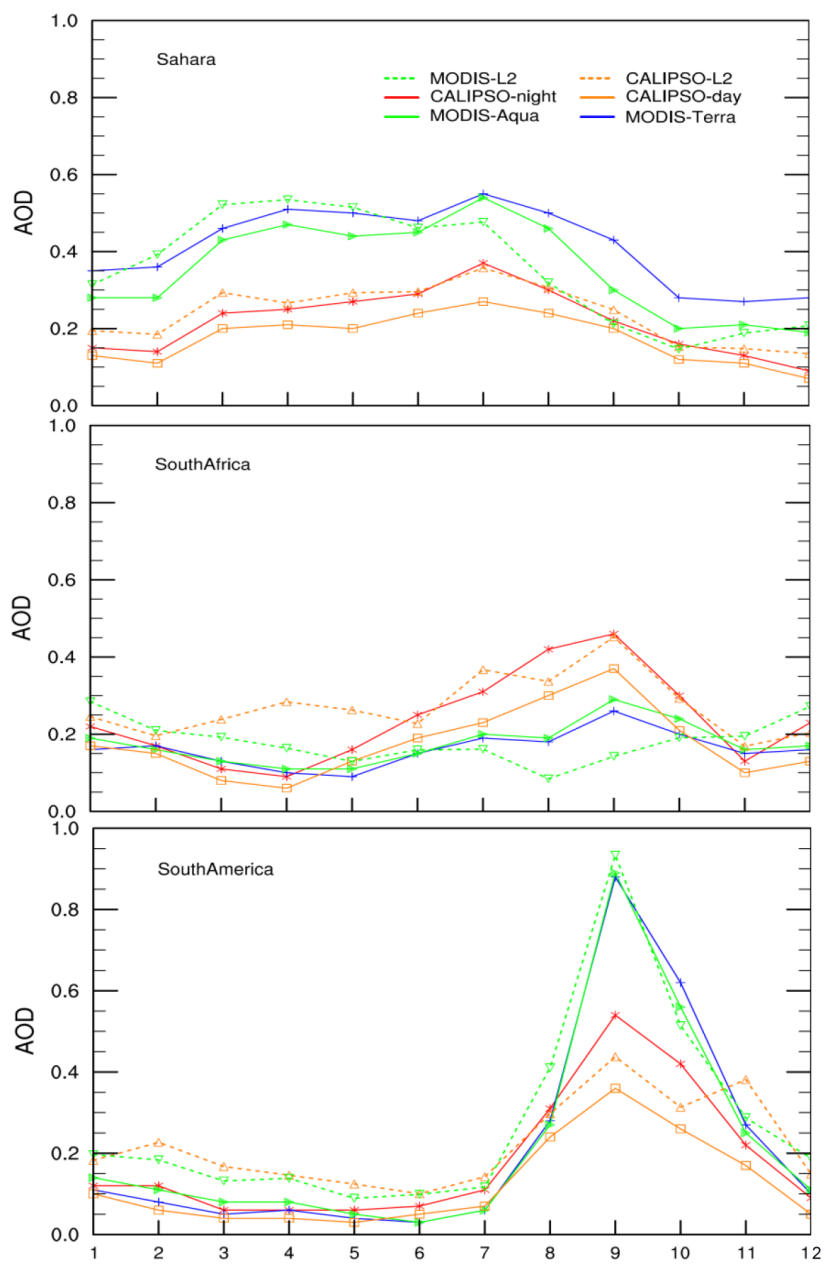

Fig. 11. Time series of AOD from level 3 (in solid curves, as shown in Fig. 5) as well as level 2 (in dashed curves) CALIPSO and MODIS over the Sahara, South Africa, and South America in 2007. The results in Northwest China are not shown due to missing values over the region shown in Fig. 10.

CALIOP (both daytime and nighttime) for the same time period over the Sahara, South Africa, and South America. It is evident that, while there exist some differences in AOD between level 2 and level 3 data, the systematic difference between CALIOP and MODIS that we discussed above can clearly be seen, i.e., CALIOP is systematically higher than MODIS over the Sahara, but lower over South Africa, and much higher over South America during biomass burning season.

\section{Summary and discussion}

In this study, we compared CALIPSO daytime/nighttime $\mathrm{AOD}$ at $532 \mathrm{~nm}$ and MODIS Terra/Aqua AOD at $550 \mathrm{~nm}$ by using aerosol retrieval data from June 2006 through the end of 2011. It is found that CALIPSO AOD is generally lower than MODIS AOD, whether day or night, Terra or Aqua products are used, due to lower frequencies in the former for most of the bins of AOD values. Correlations between CALIPSO and MODIS are relatively better over ocean than over land.

It is interesting to see that CALIPSO AOD is systematically higher than MODIS AOD over major biomass burning regions (e.g., South Africa) during the biomass burning season (July to September), but lower than MODIS over major mineral dust regions (e.g., the Sahara) and during the active dust season (summer over the Sahara). A recent study by Lee et al. (2012) shows that when the nonsphericity of dust particles is not considered in the MODIS retrieval, AOD can be underestimated, as the phase function of spherical assumption is higher than that of nonspherical assumption for the backward scattering, i.e., the geometry for the satellite retrieval. Thus, with the same reflectance measured from the satellite, the current MODIS retrieval underestimates the AOD. Therefore, if we took the effect of nonspherical dust into account, the CALIPSO AOD would be even lower than MODIS. Combined with the GEOS-Chem-APM-simulated aerosol AOD for each aerosol component during the same time period, we investigated the time series over the four regions including the Sahara, NWChina, South Africa, and South America. Our analysis shows that CALIPSO AOD is systematically lower than MODIS AOD over the Sahara and NWChina, with the maximum differences occurring during the active dust seasons, i.e., summer over the Sahara and spring over NWChina. Since dust particles contribute less to the total AOD over NWChina than the Sahara for each year, the difference of CALIPSO relative to MODIS is smaller over NWChina. While the contribution from SP is quite large for both South Africa and South America, the OC/BC contribution is much larger over South Africa than South America, which leads to a larger bias for CALIPSO relative to MODIS. The differences between CALIPSO and MODIS over South America are generally small, except during the biomass burning seasons with exceptionally high OC/BC contributions in 2006, 2007, and 2010.

To address the differences in spatial and temporal sampling, we also employed one-year (2007) level 2 CALIPSO and MODIS products for the collocated comparisons. Spatial distribution and time series show that there are indeed some differences from collocated data relative to the monthly data, but the differences do not affect our findings discussed above.

This study indicates that satellite retrieval algorithms, e.g., lidar ratios used in CALIPSO retrievals or assumptions made in MODIS algorithms, such as single scattering albedo or other aspects utilized by the aerosol models, may not work well over the strong dust and biomass burning regions and/or during their active seasons. Further research is needed to identify the reasons for this difference and to improve the satellite AOD retrievals. 
Acknowledgements. This study is supported by NASA under grant NNX11AQ72G and NSF under grant AGS-0942106. CALIPSO aerosol data were obtained from the NASA Langley Research Center Atmospheric Science Data center (ASDC). MODIS AOD data were downloaded using the GES-DISC Interactive Online Visualization and Analysis Infrastructure, a part of the NASA's Goddard Earth Sciences Data and Information Services Center and AERONET data were obtained from NASA Goddard Space Flight Center. The GEOS-Chem model is managed by the Atmospheric Chemistry Modeling Group at Harvard University with support from NASA's Atmospheric Chemistry Modeling and Analysis Program.

Edited by: P. K. Bhartia

\section{References}

Bey, I., Jacob, D. J., Yantosca, R. M., Logan, J. A., Field, B., Fiore, A. M., Li, Q., Liu, H., Mickley, L. J., and Schultz, M.: Global modeling of tropospheric chemistry with assimilated mete-orology: Model description and evaluation, J. Geophys. Res., 106, 23073-23096, 2001.

Bond, T. C., Ehardwaj, E., Dong, R., Jogani, R., Jung, S., Roden, C., Strrets, D. G., and Trautmann, N. M.: Historical emissions of black and organic carbon aerosol from energy related combustion, 1850-2000, Global Biogeochem. Cy., 21, GB2018, doi:10.1029/2006GB002840, 2007.

Guenther, A., Karl, T., Harley, P., Wiedinmyer, C., Palmer, P. I., and Geron, C.: Estimates of global terrestrial isoprene emissions using MEGAN (Model of Emissions of Gases and Aerosols from Nature), Atmos. Chem. Phys., 6, 3181-3210, doi:10.5194/acp-63181-2006, 2006.

Holben, B. N., Eck, T. F., Slutsker, I., Tanré, D., Buis, J. P., Setzer, A., Vermote, E., Reagan, J. A., Kaufman, Y. J., Nakajima, T., Lavenu, F., Jankowiak, I., and Smirnov, A.: AERONET - A federated instrument network and data archive for aerosol characterization, Remote Sens. Environ., 66, 1-16, 1998.

Kaufman, Y. J., Tanré, D., Remer, L. A., Vermote, E. F., Chu, A., and Holben, B. N.: Operational remote sensing of tropospheric aerosol over the land from EOS-MODIS, J. Geophys. Res., 102, 17051-17061, 1997.

Kim, S.-W., Berthier, S., Raut, J.-C., Chazette, P., Dulac, F., and Yoon, S.-C.: Validation of aerosol and cloud layer structures from the space-borne lidar CALIOP using a ground-based lidar in Seoul, Korea, Atmos. Chem. Phys., 8, 3705-3720, doi:10.5194/acp-8-3705-2008, 2008.

King, M., Menzel, W. P., Kaufman, Y. J., Tanre, D., Gao, B., Platnick, S., Ackerman, S. A., Remer, L. A., Pincus, R., and Hubanks, P. A.: Cloud and aerosol properties, precipitable water, and profiles of temperature and water vapor from MODIS, IEEE T. Geosci. Remote, 41, 442-458, 2003.

Kittaka, C., Winker, D. M., Vaughan, M. A., Omar, A., and Remer, L. A.: Intercomparison of column aerosol optical depths from CALIPSO and MODIS-Aqua, Atmos. Meas. Tech., 4, 131-141, doi:10.5194/amt-4-131-2011, 2011.

Lee, J., Kim, J., Yang, P., and Hsu, N. C.: Improvement of aerosol optical depth retrieval from MODIS spectral reflectance over the global ocean using new aerosol models archived from AERONET inversion data and tri-axial ellipsoidal dust database,
Atmos. Chem. Phys., 12, 7087-7102, doi:10.5194/acp-12-70872012, 2012.

Levy, R. C., Remer, L. A., Mattoo, S., Vermote, E., and Kaufman, Y. J.: Second-generation algorithm for retrieving aerosol properties over land from MODIS spectral reflectance, J. Geophys. Res., 112, D13211, doi:10.1029/2006JD007811, 2007.

Ma, X., Yu, F., and Luo, G.: Aerosol direct radiative forcing based on GEOS-Chem-APM and uncertainties, Atmos. Chem. Phys., 12, 5563-5581, doi:10.5194/acp-12-5563-2012, 2012.

Mamouri, R. E., Amiridis, V., Papayannis, A., Giannakaki, E., Tsaknakis, G., and Balis, D. S.: Validation of CALIPSO spaceborne-derived attenuated backscatter coefficient profiles using a ground-based lidar in Athens, Greece, Atmos. Meas. Tech., 2, 513-522, doi:10.5194/amt-2-513-2009, 2009.

Sassen, K.: Lidar backscatter depolarization technique for cloud and aerosol research, in Light Scattering by Nonspherical Particles: Theory, Measurements, and Geophysical Applications, edited by: Mishchenko, M. L., Hovenier, J. W., and Travis, L. D., 393416, Academic Press, San Diego, 2000.

Redemann, J., Vaughan, M. A., Zhang, Q., Shinozuka, Y., Russell, P. B., Livingston, J. M., Kacenelenbogen, M., and Remer, L. A.: The comparison of MODIS-Aqua (C5) and CALIOP (V2 \& V3) aerosol optical depth, Atmos. Chem. Phys., 12, 3025-3043, doi:10.5194/acp-12-3025-2012, 2012.

Remer, L. A., Kaufman, Y. J., Tanré, D., Mattoo, S., Chu, D. A., Mattins, J. V., Li, R. R., Ichoku, C., Levy, R. C., Kleidman, R. G., Eck, T. F., Vermote, E., and Holben, B. N.: The MODIS algorithm, products and validation, J. Atmos. Sci., 62, 947-973, 2005.

Schuster, G. L., Vaughan, M., MacDonnell, D., Su, W., Winker, D., Dubovik, O., Lapyonok, T., and Trepte, C.: Comparison of CALIPSO aerosol optical depth retrievals to AERONET measurements, and a climatology for the lidar ratio of dust, Atmos. Chem. Phys., 12, 7431-7452, doi:10.5194/acp-12-7431-2012, 2012.

Torres, O., Chen, Z., Jethva, H., Ahn, C., Freitas, S. R., and Bhartia, P. K.: OMI and MODIS observations of the anomalous 20082009 Southern Hemisphere biomass burning seasons, Atmos. Chem. Phys., 10, 3505-3513, doi:10.5194/acp-10-3505-2010, 2010.

Winker, D. M., Pelon, J., and McCormick, M. P.: The CALIPSO mission: Spaceborne lidar for observations of aerosols and clouds, Proc. SPIE Int. Soc. Opt. Eng., 4893, 1-11, 2003.

Winker, D. M., Vaughan, M. A., Omar, A., Hu, Y., Powell, K. A., Liu, Z., Hunt, W. H., and Yong, S. A.: Overview of the CALIPSO mission and CALIOP data processing algorithms, J. Atmos. Ocean. Tech., 26, 2310-2323, doi:10.1175/2009JTECHA1281.1, 2009.

Winker, D. M., Pelon, J., Coakley, J. A., Ackerman, S. A, Charlson, R. J., Colarco, P. R., Flamant, P., Fu, Q., Hoff, R. M., Kittaka, C., Kubar, T. L., LeTreut, H., McCormick, M. P., Megie, G., Poole, L., Powell, K., Trepte, C., Vaughan, M. A., and Wielicki, B. A.: The CALIPSO Mission: A Global 3D View of Aerosols and Clouds, B. Am. Meteorol. Soc., 91, 1211-1229, doi:10.1175/2010BAMS3009.1, 2010.

Winker, D. M., Tackett, J. L., Getzewich, B. J., Liu, Z., Vaughan, M. A., and Rogers, R. R.: The global 3-D distribution of tropospheric aerosols as characterized by CALIOP, Atmos. Chem. Phys., 13, 3345-3361, doi:10.5194/acp-13-3345-2013, 2013. 
Wu, D., Wang, Z., Wang, B., Zhou, J., and Wang, Y.: CALIPSO validation using ground-based lidar in Heifei $\left(31.9^{\circ} \mathrm{N}, 117.2^{\circ} \mathrm{E}\right)$, China, Appl. Phys. B, 102, 185-195, doi:10.1007/s00340-0104243-z, 2011.

Yu, F.: Ion-mediated nucleation in the atmosphere: Key controlling parameters, implications, and look-up table, J. Geophys. Res., 114, D03206, doi:10.1029/2009JD012630, 2010.

Yu, F. and Luo, G.: Simulation of particle size distribution with a global aerosol model: contribution of nucleation to aerosol and CCN number concentrations, Atmos. Chem. Phys., 9, 76917710, doi:10.5194/acp-9-7691-2009, 2009.

Yu, F., Luo, G., Bates, T., Anderson, B., Clarke, A., Kapusin, V., Yantosca, R., Wang, Y., and Wu, S.: Spatial distributions of particle number concentrations in the global troposphere: Simulations, observations, and implications for nucleation mechanisms, J. Geophys. Res., 115, D17205, doi:10.1029/2009JD013473, 2010 .
Yu, F., Luo, G., and Ma, X.: Regional and global modeling of aerosol optical properties with a size, composition, and mixing state resolved particle microphysics model, Atmos. Chem. Phys., 12, 5719-5736, doi:10.5194/acp-12-5719-2012, 2012.

Yu, H., Chin, M., Winker, D. M., Omer, A. H., Liu, Z., Kittaka, C., and Diehl, T.: Global view of aerosol vertical distribution from CALIPSO lidar measurements and GOCART simulations: Regional and seasonal variations, J. Geophys. Res., 115, D00H30, doi:10.1029/2009JD013364, 2010.

Zarzycki, C. and Bond, T. C.: How much can the vertical distribution of black carbon affect its global direct radiative forcing?, Geophy. Res. Lett., 37, L20807, doi:10.1029/2010GL044555, 2010. 